\title{
Erratum to: Optimal minimal routing and priority assignment for priority-preemptive real-time NoCs
}

\author{
Borislav Nikolićc1,2 . Luís Miguel Pinho
}

Published online: 17 May 2017

(C) Springer Science+Business Media New York 2017

\section{Erratum to: Real-Time Syst DOI 10.1007/s11241-017-9273-8}

The original version of this article unfortunately contained an error in the author affiliation. The corresponding author, "Dr. Borislav Nikolić" is currently affiliated in "Technische Universität Braunschweig", but the work of this paper was performed and funded by CISTER/INESC-TEC, ISEP, IPP. Therefore, the corresponding author is linked to both the affiliations. This has been corrected with this erratum.

The online version of the original article can be found under doi:10.1007/s11241-017-9273-8.

$凶$ Borislav Nikolić

nikolic@ida.ing.tu-bs.de

Luís Miguel Pinho

lmp@isep.ipp.pt

1 Institute of Computer and Network Engineering, Technische Universität Braunschweig,

Braunschweig, Germany

2 CISTER/INESC-TEC, ISEP, IPP, Rua Dr. António Bernardino de Almeida 431, 4200-072 Porto, Portugal 